quent want of sharpness on one side, but the definition in the centre of the field is not injured.

To give some idea of the stars that can be seen and the value that may be given to photographic evidence of the existence or non-existence of faint stars, I give some particulars of this photograph. Without a magnifier I 24 stars are to be seen within a radius of twenty minutes of arc from the nucleus.

T have traced these (see Fig. I) so that they can be identified in the telescope ; some of them may not be less than I 3 th magnitude, possibly fainter; the bright stars marked B, C, D, and e being shown in Argelander's maps of the Northern Heavens. B and C are at the present time about the same brightness as the new star, and can be well tused to watch any variation in its light (when first seen by me on September 3 the new star was very much brighter than B cr C, almost as bright as a star I have called $\mathrm{A}$ in my note-hook that is just beyond the smaller nebula).

Using a magnifier to detect any fainter stars I find six near the nucleus: these I have shown as black dots on Fig. 2, nsing a

FIG. 2 .

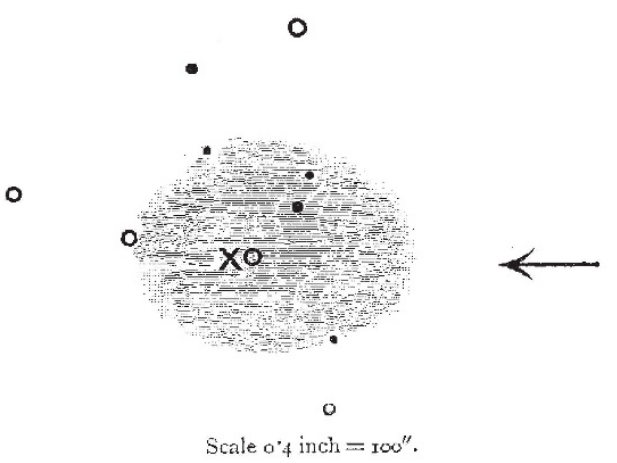

circle to show the stars near the nucleus that appear on Fig. $\mathbf{r}$, and a cross $(x)$ to indicate the place of the new star. At this particular place there is not the slightest indication of any difference in the regular shading of the deposited silver from the denser part of the nucleus to the faint edge. The six stars indicated are extremely faint in the photograph and difficult to see, but I have no doubt of their real existence; from a comparison with other photographs I estimate them of about I5th $^{\text {th }}$ magnitude, perhaps fainter. It may be that some of these may be identified at Birr Castle. From the absence of scale and orientation of the sketch given by Lord Rosse on p. 465 comparisons cannot be made, but a reference to the note-books would enable this to be done.

A. A. Common

DCRING last week I examined on three evenings the spectrum of this star apparently in the nebula. It appears to be continuous, extending from about D, as far as, or perhaps a little past F. Both Mr. Percy Smith and I are able to confirm Lord Rosse's conviction of the existence of a bright line or band. We compared its position with spark spectra, and feel satisfied that its position is not far from the bright line of the spark in air near to, and on the more refrangible side of $D$. The slit was of course necessarily wide, and the spectrum faint, so that this must only be considered as approximate.

$$
\text { Geo. M. SeABroke }
$$

Temple Observatory, Rugby, September 29

IN the first evenings of September I observed the new nucleus of the nebula in Andromeda: I find it of the 8 th magnitude. With a litile Maclean's star spectroscope applied to the ro-inch refractor the spectrum of the nucleus is continuous, with suspected brighter bands. On the nights of Sept. 14 to I6, with 340 and 470 enlargements, I found to the east of the nucleus, and $15^{\prime \prime}$ to $18^{\prime \prime}$ distant from it, a faint object, probably a second nucleus, of 12 th to $13^{\text {th }}$ magnitudes.

A. Ricco

Palermo Observatory

\section{The Proposed Change in the Astronomical Day}

In your account of the procecdings at the recent meeting of the Astronomische Gesellschaft at Geneva (NATUkE, vol. xxxii. p. 5 17 ) Dr. Struve is reported to have stated "that in the
Royal Astronomical Sociely the majority were in favour of the univeral day." There appears to be some mistake here: the Royal Astronomical Society as a body has not expressed any opinion on the subject. And, judging from the individual expressions of opinion which have been published, I should imagine that here, as at Geneva, the majority of real workers in our science (with the probable exception of those engaged on solar work) would be opposed to the proposed change. But how the majority of the Fellows of the Royal Astronomical Society could vote on the question it is impossible to say. My desire that a wrong impression on this subject, arising from a statemtent reported to have been made by such a high authority as Dr. Struve, should not be spread abroad, must be my excuse for trespassing thus far on your space.

Royal Observatory, Greenwich, S. E., September 26

\section{A Tertiary Rainbow}

Prof. TAIr remarks, in his recently-published work on "Light," that rainbows due to three or more internal reflections " are too feeble to be observed." It may therefore be worth recording that a tertiary bow was clearly visible from Thandiani Hill, Punjab, one evening last week (August I7). The bow extended over an arc greater than a semicircle, but was broken in two places. The colours were as distinct as in many an ordinary bow.

The condition of the sky was specially favourable for seeing a tertiary bow. The sun was low, and on nearly the same level with it there were several horizontal layers of cloud of considerable extent, whose nearer, unilluminated sides were therefore dark enough to serve as a good background for the bow. There was also a cloud in front of the sun itself, partially reducing its brightness.

August 25

T. C. LEWIS

\section{A White Swallow}

ON August 3 I saw a white swallow flying among its fcllows over a mill-pond at Garioch's Ford, Auchterless, Aberdeenshire. When I repassed on the following day it was still there, and it appeared to my brother and to me to be entively white: otherwise I should suggest that the one seen in Westmoreland on September 4 (NATURE, No. 830, p. 500) might be the same bird on its southward pilgrimage. If it is true that the albino bird is never courted or parred ("Descent of Man," chap. xiv.) we are not likely ever to see many white swallows.

Mirfield, Yorks, September $z 8$

Alex. ANDerson

THE enclosed paragraph from Yarmouth, in the Norfolk Neres of this day, will have interest for your correspondent at Milnethorpe.

Stoke House, Woodbridge, September 26

HubERT AIRY

Rara Avis. A cream-coloured specimen of the swallow (Hirundo arbica) was shot on Caister Road, on Monday morning last, by Mr. A. Patterson. It is now in the hands of Mr. B. Dye of Row 60 for preservation.

DURing the summer of $1883 \mathrm{Mr}$. Cooper, of Bromwich, observed a white swallow throughout the season at a place within the city on the banks of the Severn.

Worcester, September 28

THE ANNUAL CONGRESS OF THE SANITARY INSTITUTE OF GREAT BRITAIN

THE subjects dealt with by the Sanitary Institute of 1 Great Britain at its annual meetings cover a wide field, and the Leicester gathering of this year, under the presidency of Prof. de Chaumont, F.R.S., forms no exception to the rule. 'The first aim of the Institute is, through its various agencies, to assist and indeed to lead in the improvement of public health, and the President did well to prove, by mortality statistics, how great a saving of life can be effected by the adoption of efficient sanitary measures, and how remunerative expenditure in this direction proves itself to be. The result of the sanitation carried out in the Army, and which is so much due 
to the labours of the late Dr. Parkes and to those of his successor, Dr. de Chaumont, is that, comparing the results of thirty years ago with those which now obtain, there is a saving in the home Army of two battalions per annum. Some substantial progress is also being made in the same direction as regards the gencral public, and when it is more fully understood that preventible diseases as a rule destroy those members of the population who are most remunerative in so far as the State is concerned, and that, speaking generally, each such premature death means a Ioss of at least Iool., even parsimonious members of sanitary authorities will not mind expen ling a little more of the public money in so good a cause.

Leicester was well chosen for this year's gathering, for in many respects the town has acquired some reputation in health matters. It may be regarded as the headquarters of the anti-vaccination party; it prides itself, not without cause, on the efforts it has made to control the spread of infectious diseases ; and it takes precedence amongst those English towns in which autumnal diarrhœa is so fatal to the infantile population. As regards the question of vaccination it would be premature to draw any general inferences from the Leicester results, for although during recent years only a comparatively small portion of the infantile population have been vaccinated, yet a vast majority of the inhabitants are fairly well protected against small-pox, and it is by no means so very strange that a disease which usually recurs in an epidemic form only after a lapse of years, should for a time remain absent from Leicester. Still, we frankly admit that the day of reckoning has been somewhat long in coming; but there are exceptional reasons for this. And in the first place we would note that Leicester is not so free from small-pox as is generally imagined. The Registrar-General's returns have, it is true, long shown an almost absolute blank as regards small-pox mortality there, but it must be remembered that the Leicester Small-pox Hospital, where the deaths from this disease take place, is not in the borough, and hence that the mortality occasioned is registered in altogether another district. Then again, the sanitary authority of Leicester, by the aid of a system of compulsory notification of infectious diseases, acquire the earliest knowledge as to the existence of cases of small-pox, and having provided themselves with an isolation hospital, the patients are at once removed, and their houses and clothing are efficiently disinfected. It may be said that any other town could do the same, and so vaccination would become unnecessary. But this is not so. Removal to hospital is only compulsory under conditions which, were objection raised to it by the people, would make this early isolation impracticable, and all populations are not so proud of their defiance of one of the laws of the country as to submit without resistance to the steps which are held necessary in order to prove that this law is a superfluous one. But Leicester goes much further than this. The authorities not only remove the sick, but they remove the healthy members of the sick person's family, and hold them in a species of quarantine until they know that they have escaped infection. Such a step may be very desirable from a health point of view, but it is altogether illegal, and it is quitc certain that if any attempt were made to enforce such a system in other parts of the kingdom it would be resisted. The majority of the nation would also hold it to be unnecessary ; and the recent publication by the German Government of the Report of a Commission showing that since re-vaccination was made compulsory in 1874 not a single death from small-pox has occurred in their Army, affords ample evidence that the simple operation of vaccination can fully meet all the difficulty.

But little further light was thrown, at the meeting, upon that obscure zymotic diarrhoa which annually causes so large a mortality in Leicester. But Dr. E. W. Buck, who has made the subject a special study, probably pointed out the essential cause of this fatality by showing how a large portion of the population of Leicester was exposed to the influence of a watcr-logged soil charged with decomposing organic matter. Temperature so largely influences this mortality that it was at one time regarded as its sole cause; but it is certain that a high temperature alone is powerless to produce it, whereas the effect of temperature on such conditions as obtain in Leicester must be very potent in favouring the development of organic germs, such as are now supposed to lie at the root of the evil. Extensive inquiry is needed as to this subject, and we hope that the results of the investigation which have been conducted for some years past by the Medical Department of the Local Government Board will soon be made public.

Amongst the many other matters of interest which were deait with at the Congress is that of the provision of dwelling-accommodation for the working classes, and in view of the steadily extending practice of massing together vast numbers of human beings in great buildings where storey is piled upon storey, the warning uttered by Mr. Gordon Smith, President of the Engineering and Architectural Section, and the occupant of an important official appointment which adds weight to his opinion, should receive careful consideration. He asserts that in this class of buildings there has been an excessive infantile death-rate, and it is certain that the provision of ample open space about dwellings, which is, as regards ordinary dwellings, being more insisted on than ever, is especially necessary in the interests of child-life, which is so extremely sensitive to such insanitary surroundings as influence the quality of the air breathed.

The question of a rational system of burial was discussed at the last meeting of the Congress in connection with a paper by the Rev. F. Lawrence, who quoted the authority of the burial service of the Church of England as suggesting a system which would allow of the rapid action of the soil upon the dead, and who advocated burial at a depth of three or four feet only in coffins designed to ensure speedy perishability, and laid singly at a depth of three or four feet only from the surface. The advocates of cremation were naturally represented, but the progress of this method for the disposal of the dead is hindered by considerations which it is not easy to overcome. Foremost amongst these stands the difficulty of tracing cases of poisoning, and, even if the public were ready to assent generally to post-mortem examinations before the cremation was carried into effect, no such examination as is usually carried out could be trusted to decide whether this species of crime was the cause of death or not. Indeeed, in many cases of poisoning the most skilled pathological and chemical knowledge is required in order to avoid error. On the whole, such discussions as have taken place at Leicester tend to improvement in matters where change is desirable in the interests of public health, and the Institute may be congratulated on the results of their recent meeting.

\section{INSECT RAVAGES}

$T \mathrm{HE}$ preservation of our garden and field crops from the attacks of injurious and destructive insects is a study which Miss E. A. Ormerod has made specially her own and which she has carried out with such signal success. Miss Ormerod's labours in popularising the subject so as to bring it within the knowledge of all classes in any way connected with agricultural and gardening pursuits ate too well known to need even a reference, so thoroughly has she at heart the welfarc of our food crops and field produce that she has taken other steps, besides the dissemination of her well known books, to bring the importance of the subject before those who are not likely to be reached by the works in question. We refer to the 